\title{
Criação de sinais para facilitar o ensino e a aprendizagem de surdos em ciências e biologia
}

\author{
Daniela Copetti Santos ${ }^{1}$ \\ Cátia Roberta de Souza Schernn ${ }^{2}$ \\ Juliane Oberoffer Santos da Rosa ${ }^{3}$ \\ Josiane Fiss Lopes ${ }^{4}$ \\ Fabiani Machado Machado ${ }^{5}$ \\ Larissa Lunardi Lunardi ${ }^{6}$ \\ Juliane Ditz Knob ${ }^{7}$ \\ Maira Ilisa Fauth ${ }^{8}$
}

\section{Resumo}

A pesquisa teve como propósito mostrar a necessidade da criação de novos sinais para a Língua Brasileira de Sinais - Libras, em termos utilizados no ensino de Ciências e Biologia, os quais serão abordados com imagens, conceitos e sinais e, assim, proporcionar de fato um ensino pautado na proposta bilíngue para surdos. Inicialmente buscou-se ter conhecimento dos sinais existentes na área através de uma pesquisa em sites da web, conversa com alunos surdos, docentes e intérpretes. A partir disso realizou-se um levantamento de todos os termos específicos de Ciências e Biologia, e desenvolveu-se um guia de bolso com um sinalário, o qual estará disponível futuramente no formato de aplicativo de celular, intitulado "BioHand Talk". Como resultado observou-se que somente com a interação entre aluno surdo, intérprete e professor, e também com o conhecimento da estrutura gramatical, as quais envolvem os cinco parâmetros da Libras e o conhecimento dos conceitos de Ciências e Biologia, para a criação de sinais, sendo assim possível desenvolver novos sinais. Estes sinais criados somente podem se tornar oficiais e definitivos da língua se houver a aprovação da comunidade surda. Desta forma, a fim de exemplificar, são utilizados a palavra, seu conceito, a imagem representativa do termo e o sinal criado ou existente. Conclui-se que a criação e elaboração de novos sinais em Libras poderão contribuir no ensino e aprendizagem de alunos surdos nos conteúdos de Ciências e Biologia, facilitando o acesso através da ferramenta tecnológica.

1 Doutora em Ciências Biológicas - Bioquímica pela Universidade Federal do Rio Grande do Sul. Professora efetiva do Instituto Federal Farroupilha e-mail: daniela.copetti@iffarroupilha.edu.br

2 Mestranda no programa de Pós-Graduação Em Educação nas Ciências da UNIJUÍ (2018), Docente de Libras no Instituto Federal Farroupilha - Santa Rosa. E-mail: catia.schernn@iffarroupilha.edu.br.

3 Pós-Graduada em Libras - Tradução/Interpretação LIBRAS/PORTUGUÊS e PORTUGUÊS/LIBRAS e Docência - UNINTESE Paraná. (2009). Pós-Graduação em Educação Especial Inclusiva - UNINTER - Paraná. (2018). Tradutora/intérprete de Língua Brasileira de Sinais do Instituto Federal Farroupilha, Campus Santa Rosa, E-mail: juliane.rosa@iffarroupilha.edu.br.

4 Pós-graduanda em Libras e Educação de Surdos (2019) pela Anhanguera, Pós-graduanda em Psicopedagogia clínica e institucional (2019) pela Faveni, Docente de Libras, Ciências e Biologia no Estado do Rio Grande do Sul, E-mail: faberfiss@gmail.com

5 Pós-Graduanda em Educação do Meio Ambiente (2019) pela Faveni. Graduada em Licenciatura em Ciências Biológicas, Instituto Federal Farroupilha- Campus Santa Rosa /RS, E-mail: fabianimachado.1@gmail.com

6 Mestranda no Programa de Pós-Graduação em Ensino de Ciências da Universidade Federal Fronteira Sul UFFS (2019). Graduada em Licenciatura em Ciências Biológicas, Instituto Federal Farroupilha- Campus Santa Rosa /RS, E-mail: larissalunardi@outlook.com

7 Graduada em Licenciatura em Ciências Biológicas pelo Instituto Federal de Ciências e Tecnologia Farroupilha Campus Santa Rosa, julianeditz@hotmail.com.

8 Graduada em Licenciatura em Ciências Biológicas, Instituto Federal Farroupilha- Campus Santa Rosa /RS, Email: maiihb@hotmail.com 
Palavras-Chave: Ciências Biológicas. Libras. Surdo.

\begin{abstract}
The research aimed to show the need for the creation of new signals for the Brazilian Language of Signals Pounds, in terms used in the teaching of Science and Biology, which will be approached with images, concepts and signals and, thus, provide a teaching based on the bilingual proposal for the deaf. Initially we sought to be aware of the signs in the area through a search on web sites, talk with deaf students, teachers and interpreters. From this, a survey of all specific terms of Science and Biology was developed, and a pocket guide with a signage was developed, which will be available in the future in the form of a mobile application entitled "BioHand Talk". As a result it was observed that only with the interaction between deaf student, interpreter and teacher, and also with the knowledge of the grammatical structure, which involve the five parameters of the Libras and the knowledge of the concepts of Sciences and Biology, for the creation of signs, so it is possible to develop new signals. These created signs can only become official and definitive language if there is the approval of the deaf community. In this way, in order to exemplify, the word, its concept, the representative image of the term and the sign created or existing are used. It is concluded that the creation and elaboration of new signs in Libras could contribute in the teaching and learning of deaf students in the contents of Sciences and Biology, facilitating the access through the technological tool.
\end{abstract}

Key-words: Biological Sciences. Pounds. Deaf.

\title{
1 Introdução
}

O direito de todos à educação, sem discriminação de qualquer tipo, está formalmente assegurado na Constituição Federal de 1988. Mas em termos práticos, esse direito é atendido quando se trata do respeito às diferenças na igualdade de direitos no ambiente escolar? Com relação à educação das pessoas surdas Dorziat (2009, p. 71) ressalta que "uma das dificuldades mais aparentes de inserção dos alunos surdos em salas de aula regular diz respeito ao tipo de comunicação usado nesses ambientes: a comunicação oral, através da língua portuguesa". Assim, atualmente vem surgindo novas propostas para melhorar o ensino e aprendizagem desse sujeito nas salas de aula, uma dessas propostas é a comunicação bilíngue.

Na perspectiva do bilinguismo, o surdo aprende duas línguas, denominadas L1 e L2. A primeira língua (L1) deve ser sempre a de sinais, visto que essa é considerada a língua natural dos surdos, a que aprende espontaneamente e com mais facilidade. A segunda língua (L2) deve ser a língua escrita do seu país.

Conforme Quadros (1997, p. 27):

Se a língua de sinais é uma língua natural adquirida de forma espontânea pela 
pessoa surda em contato com pessoas que usam essa língua e se a língua oral é adquirida de forma sistematizada, então as pessoas surdas têm o direito de ser ensinadas na língua de sinais. A proposta bilíngue busca captar esse direito.

Nesse contexto, a Lei no 12.319 de 01/09/2010 foi de grande importância, pois regulamentou a profissão de Tradutor e Intérprete de Língua Brasileira de Sinais - Libras. No Brasil, além de ter domínio sobre a Libras, ele precisa ter o domínio do idioma falado no país, que neste caso é o português, deve conhecer processos, estratégias, técnicas de interpretação e tradução e possuir formação específica na área de atuação.

Porém, os intérpretes e professores de Libras também demonstram enfrentar vários obstáculos para a tradução de palavras para a Libras, a exemplo do componente curricular de Biologia, com sinais semelhantes para termos diferentes, confundindo os alunos surdos durante as explicações. Um exemplo são os sinais das palavras "répteis" e "serpentes", possuindo o mesmo sinal, exigindo mais tempo do intérprete para que consiga passar corretamente o sentido das frases. Além disso, muitos termos não possuem sinal e a datilologia ${ }^{9}$ é demorada, podendo dificultar o entendimento.

O objetivo dessa pesquisa foi conhecer os sinais já existentes em Ciências e Biologia, com enfoque maior na criação de sinais para todos os termos existentes em Ciências e Biologia, com o auxílio de surdos da comunidade local.

Para a criação destes sinais respeitou-se os cinco (5) parâmetros da Libras, os quais representam: Configuração das Mãos (CM), Locação (L), Movimento (M), Orientação (O) e Expressões não manuais (ENM).

\section{Conhecendo os parâmetros da Libras}

Os principais parâmetros para a organização de um sinal, segundo as autoras Quadros \& Karnopp (2004, p. 51), são: locação (L), movimento (M) e configuração de mão (CM). Além desses parâmetros básicos Gesser (2009, p. 14-18), destaca outros dois parâmetros na configuração de um sinal que foram reconhecidos a partir da década de 1970: a orientação

\footnotetext{
${ }^{1}$ Uso do alfabeto manual da Libras, quando a palavra não possui um sinal próprio.
} 
da palma da mão(O) e as expressões não manuais (ENM).

A Linguística de Corpus ocupa-se da coleta e exploração de corpora, ou conjuntos de dados linguísticos textuais que foram coletados criteriosamente com o propósito de servirem para a pesquisa de uma língua ou variedade linguística. Como tal, dedica-se à exploração da linguagem através de evidências empíricas, extraídas por meio de computador. (SARDINHA, 2000, p.2)

A sintaxe de Libras não lembra a lógica da língua portuguesa, essa é umas das dificuldades dos aprendizes ouvintes ao estudar Libras, porque se pensa na ordem das palavras do português dentro de uma frase e fazer a sinalização a partir da estrutura oral, produzindo o que se denomina de português sinalizado. Outra característica de quem está aprendendo Libras se dá quanto à falta de marcação de tempo nas formas verbais ou de flexão de número e gênero, pois os verbos em Libras têm o mesmo sinal sem conjugação no momento da conversa entre os surdos. Na Libras, esses aspectos são marcados com elementos espaciais, e não morfossintaticamente, como acontece em português (FERNANDES, 2012). O verbo RESPONDER é um exemplo, que são marcados pela direcionalidade do sinal, ou seja, pelo movimento que se faz do argumento sujeito na direção do argumento objeto. Quando o surdo está conversando com alguém sempre fará esse mesmo sinal, em todos os tempos verbais, o que irá determinar flexão será os parâmetros da Libras (QUADROS \& KARNOPP, 2004).

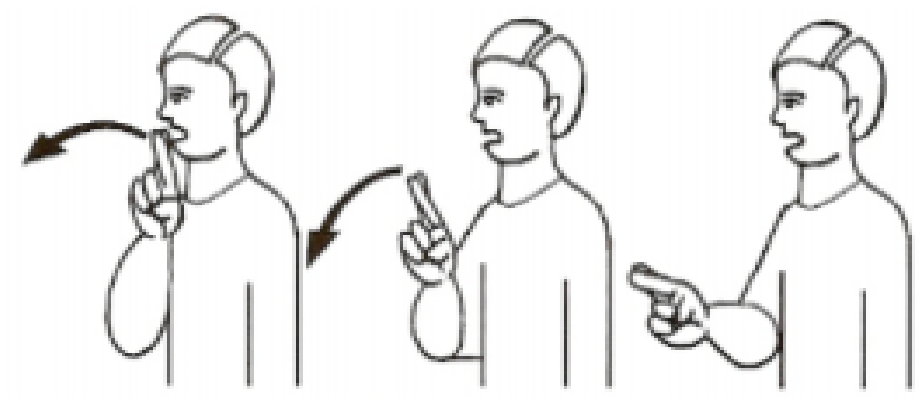

Figura 1: Movimento morfossintático Sujeito-Objeto Fonte: Capovilla e Raphael (2001, p. 1138)

Para entender um pouco mais sobre os parâmetros que formam um sinal se verificará como acontece cada um deles. 
Configuração de mão (CM): refere-se às formas que as mãos assumem na produção dos sinais, que podem ser da datilologia (FERNANDES, 2012).

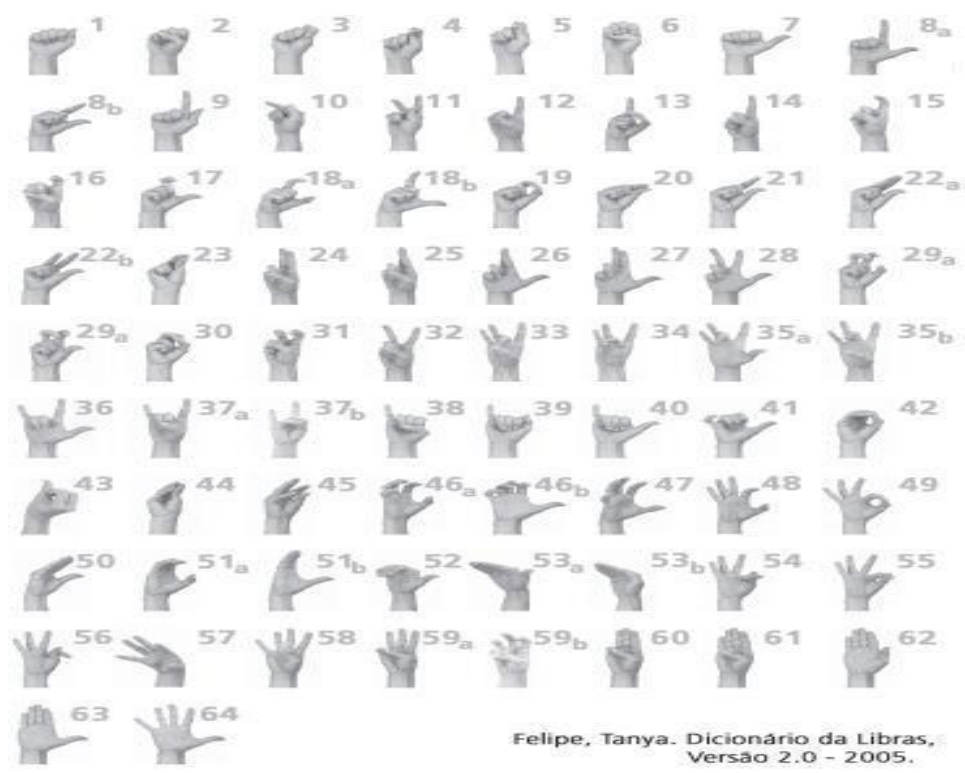

Figura 2: Dicionário de Libras

Fonte: Felipe e Monteiro (2006, p. 28)

Apesar de existir outros quadros oficiais de configuração de mão, cada qual seguindo as diferentes abordagens de seus autores, em que cada autor propõe um agrupamento diferente na quantidade de configurações de mãos, utilizamos o quadro da a autora Tanya Felipe (2006), pois possui maior visibilidade e quantidade razoável de configuração de mãos. A autora identificou sessenta e quatro configurações de mãos, elas são feitas pela mão dominante (mão direita para os destros, assim como podem ser realizados com a mão esquerda para os canhotos), ou também pelas duas mãos. Dependendo do sinal cada configuração de mão representa um número de sinais (FELIPE; MONTEIRO, 2006).

Por exemplo, ao fazer a configuração de mão número dois do quadro acima, é possível realizar vários sinais como: 


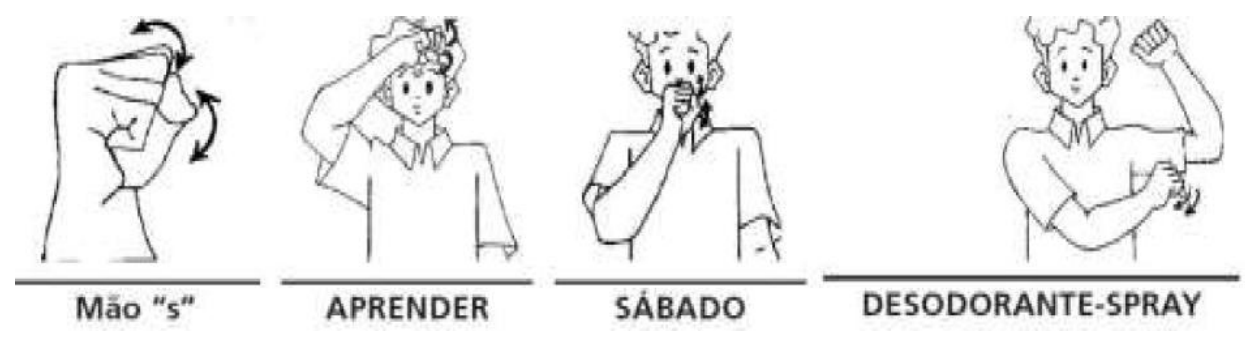

Figura 3: Configuração de mãos para o número 2

Fonte: Felipe e Monteiro (2006, p. 21)

Locação (L): ou ponto de articulação, é a área no corpo ou no espaço de articulação definido pelo corpo, em que o sinal é articulado, podendo a mão tocar o corpo ou estar em um espaço neutro vertical (do meio do corpo até a cabeça), ou horizontal (à frente do emissor) (QUADROS \& KARNOPP, 2004, p. 57). Por exemplo, os sinais que seguem: TRABALHAR, BRINCAR, PAQUERAR são feitos no espaço neutro e os sinais ESQUECER, APRENDER e DECORAR são realizados na testa:
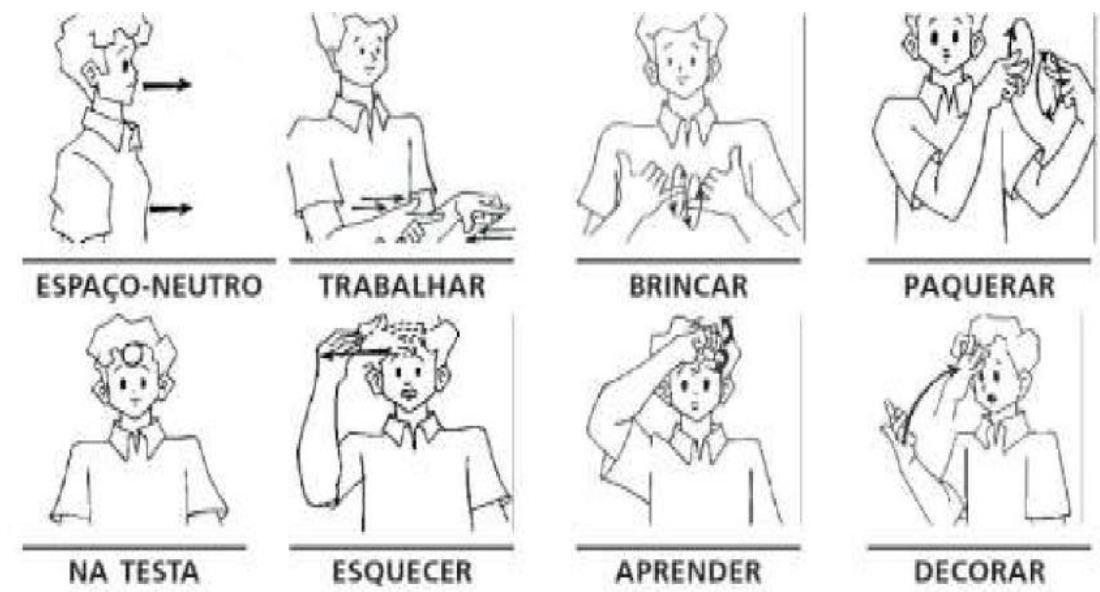

Figura 4: Pontos de articulação

Fonte: Felipe e Monteiro (2006, p. 22)

Movimento (M): são todos os movimentos realizados, desde os movimentos internos da mão, os movimentos do pulso e os movimentos direcionais no espaço até o conjunto de movimentos no mesmo sinal ( $\mathrm{CHOl}$ et al., 2011, p. 64). Os sinais podem ter ou não movimentos. Por exemplo, RIR, CHORAR e CONHECER tem movimento, já os sinais AJOELHAR, EM PÉ, SENTAR não tem movimento. 


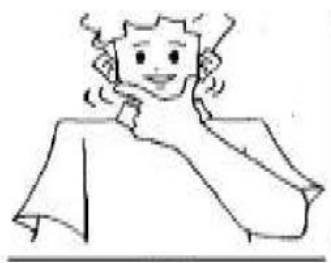

RIR

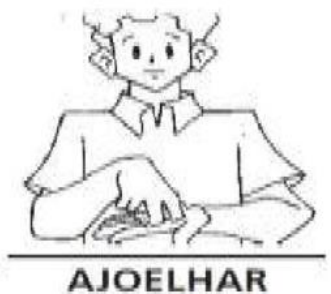

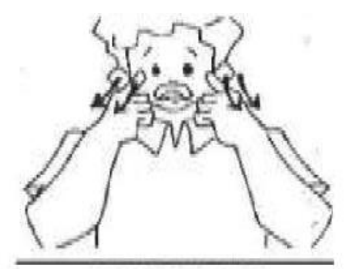

CHORAR

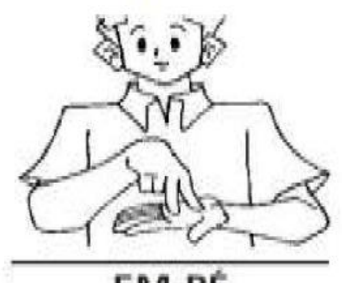

EM-PE

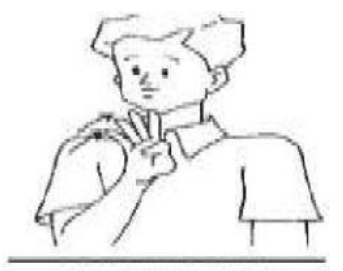

CONHECER

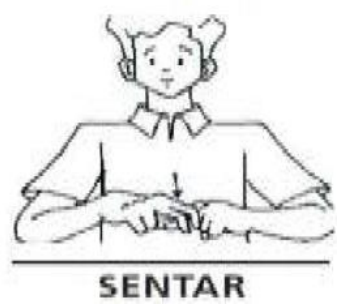

Figura 5: Sinais com e sem movimento

Fonte: Felipe e Monteiro (2006, p. 22)

Orientação (0): é a direção para qual a palma da mão aponta na produção do sinal (CHOI et al., 2011, p. 65). Assim, os verbos IR e VIR se opõem em relação à direcionalidade, como os verbos SUBIR e DESCER, ACENDER e APAGAR, ABRIR e FECHAR.

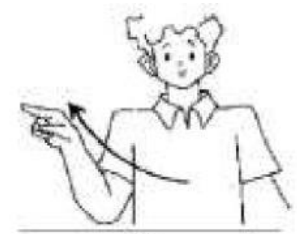

IR

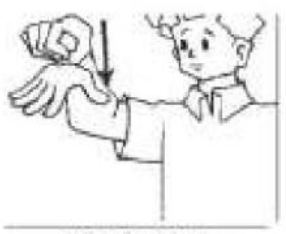

ACENDER
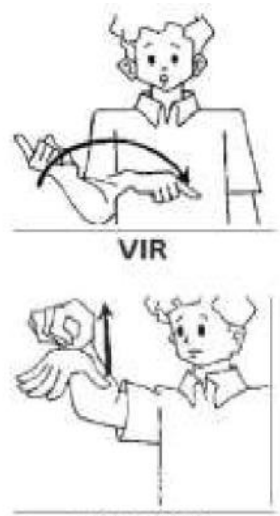

APAGAR

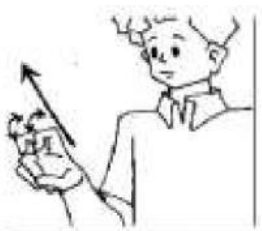

SUBIR

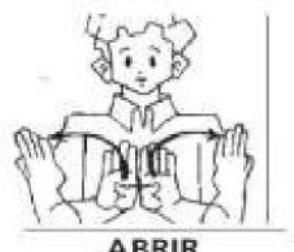

ABRIR

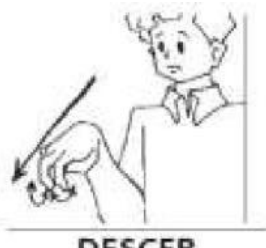

DESCER

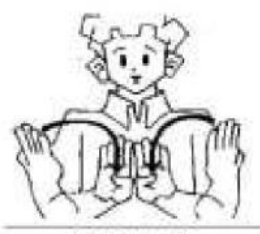

FECHAR

Figura 6: Orientação dos sinais

Fonte: FELIPE; MONTEIRO, 2006, p. 23.

Expressões não manuais (ENM): esse parâmetro é muito importante também, pois ele fará o complemento dos demais parâmetros tornando o sinal mais claro e incisivo. Na sua configuração tem um aspecto diferenciador que é a expressão facial e/ou corporal. É nesse 
parâmetro que vai ser determinado a intensidade do sinal, ou até mesmo se é uma pergunta, afirmação ou negação, como os sinais ALEGRE e TRISTE. Há sinais feitos somente com a bochecha, são sinais mais discretos como LADRÃO, ATO-SEXUAL. E tem ainda sinais em que sons e expressões faciais complementam os traços manuais, como os sinais HELICÓPTERO e MOTO (FELIPE; MONTEIRO, 2006).

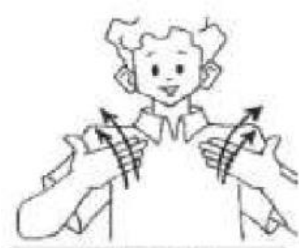

ALEGRE

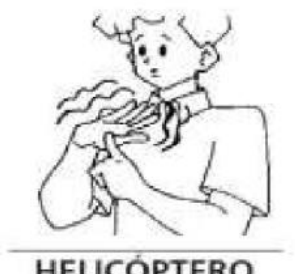

HELICÓPTERO

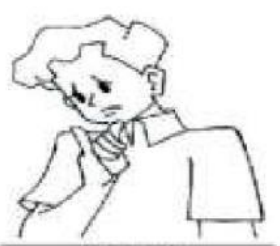

TRISTE

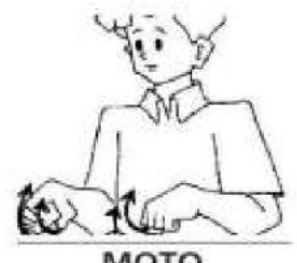

Figura 7: Expressões não manuais

Fonte: Felipe e Monteiro (2006, p. 23)

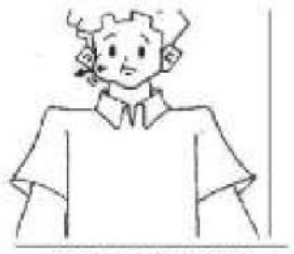

ATO-SEXUAL

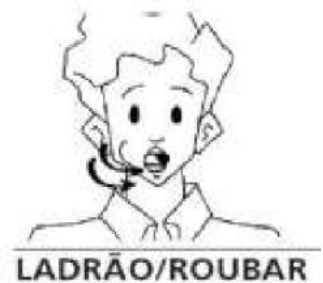

Santana (2007, p. 95) ressalta que o autor Stokoe (1972) já apontava para a importância das expressões faciais, que devem ser consideradas parte dos sinais, pois possuem papel similar ao contorno de entonação das línguas orais: afirmação, negação, dúvida, questionamento, também já exposto acima por Felipe \& Monteiro (2006). Stokoe (1972) ainda destaca que:

\begin{abstract}
Semanticamente a língua de sinais possui vocabulário menor que as línguas orais (na proporção de 1 para 100). Além do léxico menor, o autor comenta que não há, nas línguas de sinais, artigos, preposições, advérbios e cópulas. A sintaxe, por outro lado, não pode ser descrita por generalização de regras desse gênero, e pode fornecer dados sobre a estrutura profunda da linguagem (SANTANA, 2007, p. 95). ${ }^{10}$
\end{abstract}

\footnotetext{
${ }^{2}$ A estrutura profunda é um sistema de duas proposições, nenhuma das quais é afirmativa, mas que se relacionam de tal forma que exprimem o significado da sentença. Conforme ressalta Chomsky (1971, p. 46) "o conhecimento de uma língua implica a capacidade de atrair estruturas profundas e de superfície a uma série infinita de sentenças, relacionar adequadamente essas estruturas e atribuir uma interpretação semântica e uma interpretação fonética às estruturas conjugadas, profunda e superficial. Este esboço da natureza da gramática parece internamente adequado como primeira aproximação para a caracterização do conhecimento de uma
} 
A autora Fernandes (2012, p. 85), salienta que a Libras tem uma riqueza de elementos com base na cultura visual dos surdos, na medida em que "nos oferecem um amplo universo de possibilidades de representar o mundo, encadeando as palavras, não de forma linear e sequencial como estamos acostumados na comunicação oral e também na escrita, mas de modo simultâneo e multidimensional".

Infelizmente toda essa riqueza cultural que a autora menciona é desconhecida pela maioria das pessoas, o que contribui para a compreensão de uma visão distorcida das pessoas surdas que pertencem a uma minoria linguística. A Libras é plena de forma e conteúdo, fazendo com que seus usuários não sejam monolíngues. Se por acaso isso venha a acontecer, o surdo fica marginalizado socialmente, uma que a língua portuguesa é a língua oficial do país que domina os veículos mais importantes de comunicação, e é por meio dela que são transmitidas todas as informações, redigidos documentos oficiais, a arte, enfim, ela é o elemento mediador principal para o acesso ao conhecimento.

Desta forma, na combinação destes cinco parâmetros, forma-se o sinal: "Falar com as mãos é, portanto, combinar estes elementos para formarem as palavras e estas formarem as frases em um contexto" (FELIPE; MONTEIRO, 2006, p. 23). Para conversar na Libras, isso vale para qualquer língua, não basta conhecer as palavras e articulá-las adequadamente, é preciso aprender as suas regras gramaticais, a combinação destas palavras em frases. Mas estas regras, por envolverem questões mais ligadas à linguística da Língua de Sinais não serão objeto de estudo dessa pesquisa.

A partir do conhecimento desses parâmetros pode-se pensar na criação de novos sinais para melhorar a compreensão das aulas nas disciplinas de Biologia e Ciências.

\section{A comunicação do professor e do aluno surdo na educação básica}

A sala de aula já é um desafio constante, principalmente quando se tem alunos com

língua".

LínguaTec, Instituto Federal de Educação, Ciência e Tecnologia do Rio Grande do Sul, Bento Gonçalves v. 3, n. 1, p. 71-91, jun. 2019. 
necessidades educacionais especiais, no qual requer mais uma preparação teórico/metodológica para que esses alunos tenham aprendizado significativo e se desenvolva de maneira eficaz e prazerosa.

As abordagens educacionais, fazem-nos refletir no ensino-aprendizagem dos surdos, na dificuldade de comunicação e relacionamento interpessoal, já que o processo educacional para o surdo deve ser voltado para a aquisição da língua de sinais, o que permite à pessoa surda viver de forma consciente, participativa, colaborativa e criativa, tornando-se construtor do seu próprio conhecimento ser enquanto sujeito cidadão. O que segundo Quadros (1996):

\begin{abstract}
A voz dos surdos são as mãos e os corpos que pensam, sonham e expressam. As línguas de sinais envolvem movimentos que podem parecer sem sentido para muitos, mas que significam a possibilidade de organizar as ideias, estruturar 0 pensamento e manifestar o significado da vida dos surdos. Pensar sobre a Surdez requer penetrar no "mundo" dos surdos e "ouvir" as mãos que com alguns movimentos nos dizem o que fazer para tornar possível o contato entre os mundos envolvidos. Permita-se a "ouvir" essas mãos. Somente assim será possível mostrar aos surdos como eles podem "ouvir" o silêncio da palavra (Quadros, 1996).
\end{abstract}

O Art. 2 do Decreto no 5.626 (BRASIL, 2005) considera a pessoa surda como sendo "aquela que, por ter perda auditiva, compreende e interage com o mundo por meio de experiências visuais, manifestando sua cultura principalmente pelo uso da Libras". O deficiente auditivo é todo aquele que possui uma perda (bilateral, parcial ou total) de quarenta e um (41) decibéis (dB) ou mais da audição (BRASIL, 2005). Todavia, verifica-se que nos Parâmetros Curriculares Nacionais (BRASIL, 1999, p. 25), a deficiência auditiva refere-se a "perda total ou parcial, congênita ou adquirida, da capacidade de compreender a fala por intermédio do ouvido", a qual acaba se manifestando em surdez leve/moderada ou surdez severa/profunda. Assim, observa-se que ambos os textos não abordam a deficiência auditiva e a surdez com a mesma definição, existindo dualidade de significados. O Decreto no 5.626 (BRASIL, 2005) considera os surdos como deficientes auditivos devido à perda da audição, e são considerados surdos apenas quando se comunicam por meio da Libras. Já os PCN integram a palavra surdez ao entendimento da perda da audição, da leve à profunda, deixando o termo surdo conectado ao significado de deficiente auditivo (MENDES, 2002).

Existem dispositivos legais na legislação brasileira para a inclusão de alunos com 
Necessidades Educativas Especiais (NEE) em escolas públicas e privadas, dentre estes se podem apontar: (1) Constituição Federal do Brasil, Art. 206, inciso I e Artigo 208; (2) Lei de Diretrizes e Bases da Educação Nacional — LDBEN, Lei 9394 de 1996, Artigo 59, incisos I e III; (3) Estatuto da Criança e do Adolescente - ECA, Lei 8069 de 1990, Art. 53, inciso I; (4) Decreto n. ${ }^{\circ}$ 5.626, 22/12/2005 que propõe a inclusão da Língua Brasileira de Sinais, doravante, Libras como objeto de ensino, pesquisa e extensão; e (5) Especificamente aos alunos deficientes auditivos - DA, cf. Lei n. ${ }^{\circ} 10.436,24 / 04 / 2002$, decorrente do Decreto n. ${ }^{\circ}$ 5.626/2005, sobre o incentivo do uso e da difusão da Libras e mais recentemente, em 2015 foi instituída a (6) Lei 13.146 destinada a Inclusão de Pessoas com Deficiência (Estatuto da Pessoa com Deficiência). Em seu artigo 3ํe é assegurado o direito à comunicação por meio da Libras, Braille, a visualização de textos, sistema de comunicação tátil, caracteres ampliados, dispositivos de multimídia, linguagem simples, escrita e oral, sistemas auditivos, meios de voz digitalizados, englobando as tecnologias de comunicação e informação. Em nível mundial, vale destacar ainda a Declaração de Salamanca, adotada pela Organização das Nações Unidas em evento na cidade espanhola de mesmo nome, ocorrido de 7 a 10 de junho de 1994, a qual busca a equidade de oportunidades para pessoas com deficiência. Entretanto, apesar de todo o aparato legal mencionado, há muito preconceito e restrição ao acesso e à permanência do aluno deficiente em escolas públicas e privadas por parte de pais, professores, gestores e alunos (GOMES, MINGUILI, 2014).

\footnotetext{
O Brasil vem evoluindo na inclusão escolar de pessoas surdas em escolas regulares, o assunto vem ganhando visibilidade, note-se o tema da redação do Exame Nacional do Ensino Médio (ENEM) em 2017: Desafios para a formação educacional de surdos no Brasil. Conforme descreve Lacerda; Albres e Drago (2013 p.67)
}

A escola regular, que acolhe todos os alunos (deveria acolher), além de oferecer apoio àqueles que encontram barreiras em sua aprendizagem, precisa apresentar meios e recursos adequados. Nesse sentido, além de um local destinado à aprendizagem da leitura e da escrita, necessita ser um espaço que oportunize a criança desvendar o mundo, assim como, aprender a conviver em sociedade. Porém, para que o aluno com deficiência que frequenta essa escola tenha garantido essa relação de aprendizagem e experiência, a acessibilidade 
precisa ser uma realidade na escola regular que recebe esse alunado (CASTRO, 2013).

Os autores Amorin, Costa e Walker (2015) chamam a atenção sobre a educação inclusiva, a qual compreendem como direito de todo cidadão, sendo base para sua formação. Por mais que o direito à educação a todos seja reconhecido, esse processo requer muito trabalho e empenho, pois na visão desses autores a inclusão de fato: “[...] é uma conquista que exige muito estudo, trabalho e dedicação de todos os envolvidos no processo do aluno: aluno surdo e ouvinte, família, professores, fonoaudiólogos, psicólogos, assistentes sociais e demais elementos da escola" (p. 2).

A inclusão começa a ser discutida com veemência na década de 1990, desencadeada por movimentos que aconteceram mundialmente e que trouxeram à tona a necessidade de se rever a educação das pessoas com deficiência, que ocorriam em um sistema educacional à parte, portanto segregado em escolas ou classes especiais.

Através dessa Declaração da Salamanca em 1994, é reafirmado o compromisso antes estabelecido com a Educação para Todos, reconhecendo a necessidade e urgência de providenciar uma educação para as crianças, jovens e adultos com deficiências, dentro do sistema regular de ensino.

Dentro da perspectiva inclusiva, acredita-se que as escolas deveriam acomodar todas as crianças independentemente de suas condições físicas, intelectuais, sociais, emocionais, linguísticas ou outras.

A Declaração de Salamanca também deixa claro que a inclusão não é apenas para as pessoas com deficiências, mas é de fato para todas as pessoas, quando proclama:

Aquelas deveriam incluir crianças deficientes e superdotadas, crianças de rua e que trabalham, crianças de origem remota ou de população nômade, crianças pertencentes a minorias linguísticas, étnicas ou culturais, e crianças de outros grupos desvantajosos ou marginalizados (UNESCO, 1994 p. 3).

A inclusão de alunos surdos na sala de aula regular torna-se muitas vezes um desafio, uma vez que há carência de profissionais Intérpretes de Libras e também muitas universidades e escolas não dispõe destes profissionais. A legislação proíbe as escolas Públicas e Privadas de recusarem matricular pessoas surdas, ou de cobrar taxas extras da 
família para que seja contratado um professor bilíngue ou intérprete de Libras, caso este profissional não faça parte do seu quadro de profissionais. A escola deve oferecer ao aluno surdo possibilidades verdadeiras de aprendizagem, caso contrário estará sendo realizada apenas uma integração ${ }^{11}$ do aluno na escola, mas ele não estará envolvido no processo de aprendizagem.

A comunicação do professor com o aluno surdo é necessária dentro desse ambiente, uma vez que esse aluno também precisa adquirir o conhecimento para a compreensão do conteúdo, assim como manter uma relação estável com o mesmo. Portanto, alguns professores ainda utilizam de métodos comunicativos arcaicos, como o oralismo ${ }^{12}$, para se expressar com esses alunos. Somente 33,3\% se comunicam através de libras e $50 \%$ através de mímica, tornando-se um desafio para se comunicar com os alunos surdos, pois os mesmos precisam se comunicar em sua língua materna (SILVA e SOUZA, 2018).

O papel do professor na investigação, planejamento e revisão dos conteúdos e da sua prática, deve ser extremamente rigoroso para que não transmita uma informação equivocada e reduzida sobre a natureza e o sentido do fenômeno que é encontrado em alguns materiais bilíngues, isso pode trazer sérias consequências de aprendizado aos alunos surdos e ouvintes: (ALVES; PEIXOTO; LIPPE, 2013). Deste modo Castro (1999) afirma que não havendo um professor preparado em Libras na sala de aula para educar os alunos surdos, é necessária a presença de um intérprete para atuar como mediador da comunicação entre professor/aluno.

A inclusão de alunos surdos na sala de aula regular torna-se muitas vezes um desafio, uma vez que há carência de profissionais Intérpretes de Libras e também muitas universidades e escolas não dispõe destes profissionais. A legislação proíbe as escolas Públicas e Privadas de recusarem matricular pessoas surdas, ou de cobrar taxas extras da

\footnotetext{
${ }^{11}$ A integração não é sinônimo de inclusão, a mera presença (integração) do aluno surdo em sala de aula não garante que ela esteja incluída no contexto escolar. Incluir vai muito além da de integrar (aceitar a matrícula do aluno com deficiência na escola), é preciso adaptar atividades na formação desse aluno, além de reforçar a relação entre escola, família e comunidade.

12 Oralismo é um método de ensino para surdos, defendido principalmente por Alexander Graham Bell (18741922) no qual se defende que a maneira mais eficaz de ensinar o surdo é através da língua oral, ou falada. Surdos que foram educados através deste método de ensino são considerados surdos oralizados.
} 
família para que seja contratado um professor bilíngue ou intérprete de Libras, caso este profissional não faça parte do seu quadro de profissionais

\section{A importância de Libras para a área de Ciências e Biologia}

O trabalho com alunos surdos é desafiador, porém motivador, principalmente ao saber que estes alunos, muitas vezes, são excluídos do meio escolar, inclusive dentro da própria sala de aula. $\mathrm{O}$ aspecto pedagógico de inclusão escolar ainda é polêmico e precisa ser discutido nos diversos segmentos da sociedade. Temos posto que está longe do ideal a preparação dos profissionais da educação para trabalhar com alunos especiais (LACERDA; SANTOS, 2013).

O ensino de Ciências e Biologia nas escolas, muitas vezes, se mostra longe da realidade de muitos alunos, seja ele surdo ou ouvinte, quando abordados os conceitos aplicados às reações que ocorrem no corpo humano ou no interior de uma célula, por exemplo.

O ensino de Ciências e Biologia, bem como outras disciplinas de base comum, é visto com certa preocupação para os alunos surdos, pois, por vezes, os conteúdos e seus conceitos são descontextualizados e ensinados de forma independente, em seus estudos sobre educação inclusiva no ensino de Ciências, Silva; Gaia (2013, p. 4) chama atenção para a importância da comunicação para o aprendizado:

Os conteúdos de Ciências muitas vezes, apresentam temas de difícil compreensão e isso pode ser um desafio para professores e alunos. As aulas práticas apresentam formas de estudos que nem sempre são acessíveis para todos, por exemplo, olhar um material no microscópio. Este e outros pontos devem ser analisados minuciosamente pelo professor para que nenhum aluno seja 'excluído' do aprendizado. Se a comunicação é deficiente estará prejudicado esse aprendizado.

Para Gomes e Basso (2014), quando se pensa em Educação Inclusiva para as Ciências Biológicas, deve-se repensar estratégias e práticas educativas que atendam a esses alunos; contudo, é plausível também fazer uso da prática reflexiva.

Note-se que os intérpretes sentem falta de materiais concretos e visuais e chamam a 
atenção do professor no que refere ao planejamento das aulas. Nesse sentido, lembramos do estudo de Santiago (2014), no qual foi perguntado às intérpretes se as mesmas gostariam de sugerir algo aos professores de Ciências que têm alunos surdos, estas enfatizaram que o sucesso desses discentes, nesta área do conhecimento, exige dos docentes a elaboração de situações de aprendizagens diversificadas. Os participantes daquele estudo recomendaram que os professores que trabalham com alunos surdos devem ter a consciência de que sua aprendizagem ocorre com o visual, oralizar apenas o conteúdo não beneficia o aluno surdo, que deve ter materiais adaptados como imagens, vídeos e livros para melhor construção do conhecimento. Dessa forma tivemos como objetivo conhecer os sinais já existentes em Ciências e Biologia, com enfoque maior na criação de sinais para todos os termos existentes nessa área, com o auxílio de surdos da comunidade local e do próprio instituto onde desenvolvemos o projeto.

\section{Estudo}

O presente estudo surgiu a partir do projeto de pesquisa desenvolvido no Instituto Federal Farroupilha - Campus Santa Rosa/RS, tendo surgido primeiramente como resultado de uma disciplina intitulada Práticas de Ensino enquanto Componente Curricular I, o qual teve o intuito de produzir um recurso metodológico, para estudantes surdos, professores e intérpretes para o ensino de Ciências e Biologia. Tendo como objetivo a criação de sinais para a área de Ciências e Biologia, tendo sido desenvolvida uma pesquisa em termos relacionados a essa área e na confirmação da não existência de sinais, para a grande maioria destes. Essa pesquisa foi realizada através de sites da internet, manuais e livros que traziam os sinais em libras dessa área e os quais já estavam disponíveis com acesso livre. A partir da criação desses sinais será desenvolvido um aplicativo de celular com o salário dos devidos termos, vídeo de curta duração e conceitos para a melhor compreensão, os quais estão sendo publicados através de um manual ilustrativo.

\subsection{Contexto e participantes}

LínguaTec, Instituto Federal de Educação, Ciência e Tecnologia do Rio Grande do Sul, Bento Gonçalves v. 3, n. 1, p. 71-91, jun. 2019. 
No desenvolvimento deste trabalho participará uma (1) professora da área de Ciências Biológicas, uma (1) professora da área de libras, uma (1) intérprete e cinco (5) alunos do Curso de Licenciatura em Ciências Biológicas, ouvintes e quinze (15) alunos surdos de diversas escolas da região. O estudo foi validado através da apresentação dos sinais criados e apresentados para três alunos surdos do Instituto visando um efetivo aprendizado, em que os discentes possam construir conhecimento que venha a qualificá-los para o mercado de trabalho e inseri-los na sociedade como um cidadão que tem seus direitos respeitados, e um indivíduo que tem capacidade de aprender desde que haja quem ensine, e que esse ensino seja de qualidade.

\section{Análise dos resultados}

Libras pode ser definida como uma língua natural dos surdos no Brasil. É uma língua no qual se utiliza as mãos, diferente dos idiomas que são orais e auditivos. É uma língua pronunciada pelo corpo e percebida pela visão. A aprendizagem de Libras requer atenção visual, discriminação visual, memória visual, expressão facial e corporal e agilidade manual, é essa língua que vai oportunizar ao surdo a construção de sua identidade. E mais importante do que falar é ser respeitado em suas diferenças, é poder ter experiências significativas que possibilitem o pleno domínio de uma língua (LOPES, 2006).

A partir da busca prévia sobre os sinais de libras já existentes relacionados a área de Ciências e Biologia foi possível pensarmos na criação de um Guia llustrativo de Sinais intitulado "O ensino de Ciências e Biologia através da criação de Sinais para a alfabetização científica $^{13}$ de surdos", o qual está apresentado na Fig. 1, com sinais que foram criados através de discussões realizadas pelos autores deste artigo e o qual encontra-se em vias de

\footnotetext{
${ }^{5}$ Segundo Cobern e Aikenhead (1998) a Alfabetização Científica (AC) caracteriza-se por ser uma via de aprendizagem em aulas de Ciências em que o aprendizado se dá por meio da aquisição de uma nova cultura, no caso, a cultura científica, considerando os conhecimentos já estabelecidos na cultura cotidiano do indivíduo. Segundo Hurd (1998) envolve a produção e utilização da Ciência na vida do homem, provocando mudanças revolucionárias na Ciência com dimensões na democracia, no progresso social e nas necessidades de adaptação do ser humano.
} 
publicação, não sendo possível incluí-lo todo nesse artigo, visto que esse Guia apresenta aproximadamente duzentas e cinquenta (250)páginas, com oito (8) capítulos, e que está separado em Biologia Celular, Botânica, Ecologia, Embriologia, Evolução, Genética, Zoologia, Algas e Fungos. Todos esses sinais foram apresentados e validados com alunos surdos da própria instituição, os quais foram fundamentais para facilitar a aprendizagem nessa área, permitindo dessa forma com que o aluno encontrasse uma forma mais concreta de aprender os conteúdos relacionados a essas disciplinas.

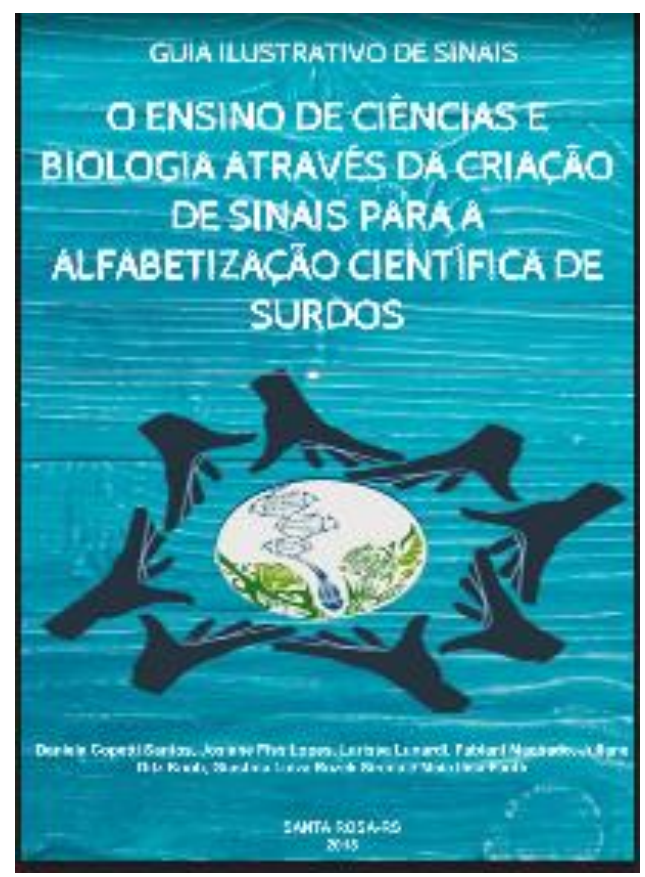

Figura 8: Guia ilustrativo com a língua de sinais na área de Ciências e Biologia.

Fonte: o autor

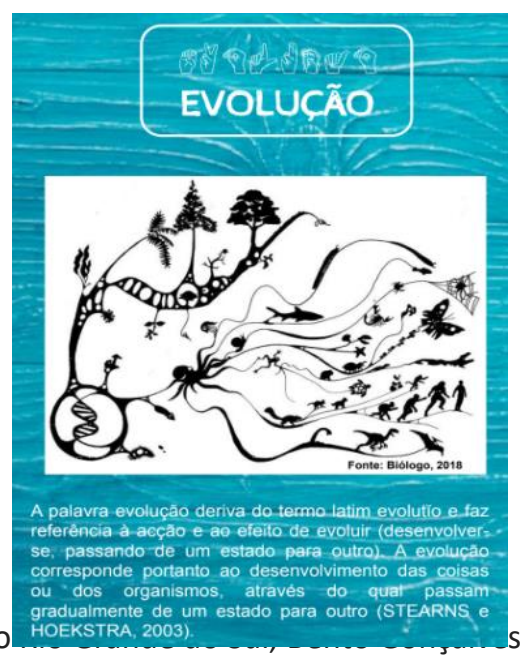




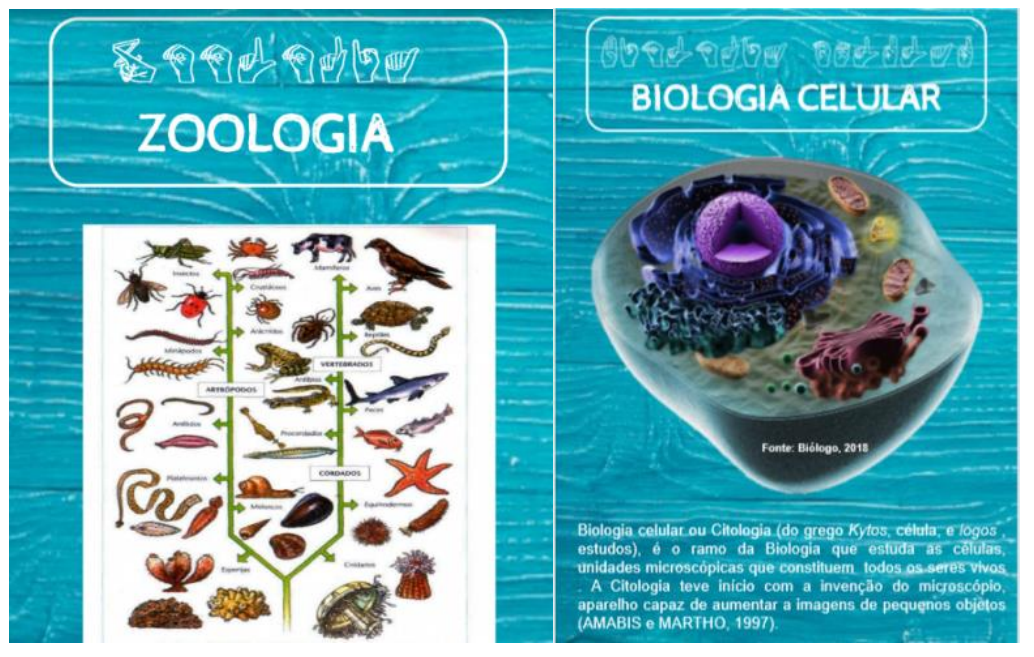

Figura 8: Alguns dos capítulos que já estão em via de publicação referentes ao Guia Ilustrativo.

Fonte: o autor

"Bio Hand Talk", sendo um importante meio de acesso às informações, principalmente de termos e conceitos biológicos, conforme mostrado na Figura 3. Importante frisar que o aplicativo ainda está sendo diagramado e logo estará disponível para acesso livre a todos os acadêmicos e para quem tiver interesse em conhecê-lo.

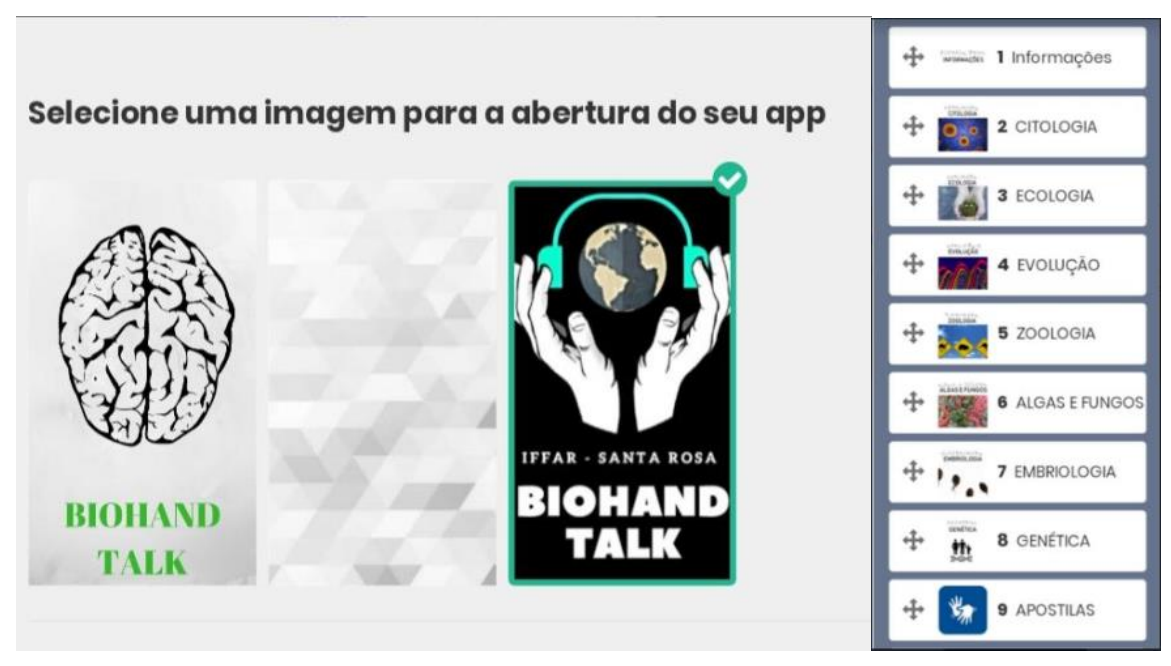

Figura 9: Foto do aplicativo e as diferentes subáreas de Ciências e Biologia.

Fonte: o autor

Tanto o Guia Ilustrativo quanto o aplicativo serão de extrema importância para um maior conhecimento na língua de sinais e para desenvolver o interesse em uma área que muitas vezes se torna tão abstrata tanto para o professor em sua maneira de ensinar quanto para os próprios alunos surdos. 


\section{Considerações finais}

A partir dos resultados obtidos, pôde-se observar que o projeto "criação de sinais para facilitar o ensino e aprendizagem de surdos em ciências e biologia", assim como o guia ilustrativo e, posteriormente, o aplicativo "BioHand Talk", apresentam grande potencial e podem contribuir para uma maior divulgação da Língua de Sinais. Sendo um importante meio de acesso às informações, principalmente de termos e conceitos biológicos.

Através do aplicativo "BioHand Talk", é possível socializar e compartilhar o aprendizado da Língua de Sinais por intérpretes, professores e alunos surdos, facilitando a comunicação e a integração dos mesmos na sociedade. Com este aplicativo, disponibiliza-se um novo recurso ao entendimento de termos e conceitos de Biologia e para comunicação entre surdos e ouvintes. Esta ferramenta demonstra um vídeo de curta duração do sinal criado, a imagem da palavra e o conceito do termo de maneira a facilitar o acesso à informação, à pesquisa e à cultura.

\section{Referências}

ALVES, F.S de; PEIXOTO, D.E.; LIPPE, E.M.O. Releitura de Conceitos Relacionados à Astronomia Presentes nos Dicionários de Libras: Implicações para Interpretação/Tradução. Rev. Bras. Ed. Esp., Marília, v. 19, n. 4, p. 531-544, Out-Dez, 2013.

AMORIN, M.; COSTA, S.; WALKER, M. A inclusão do aluno surdo na rede regular de ensino. 2015. Disponível em: <http://www.ufac.br/portal/unidadesadministrativas/orgaoscomplementares/edufac/revistas-eletronicas/revista-ramal-deideias/edicoes/edicao-

$1 /$ caminhos-da-educacao/a-inclusao-do-aluno-surdo-na-rederegular-de-ensino $>$. Acesso em 17 mar. 2019.

BRASIL. Constituição Federal. Brasília: Senado Federal, 1988. Disponível em: http://www.planalto.gov.br/ccivil 03/constituicao/constituicaocompilado.htm. Acesso em: 02 abr. 2019.

- Secretaria de Educação Fundamental. Parâmetros Curriculares Nacionais: adaptações curriculares. Brasília: MEC/SEF/SEESP, 1999.

Decreto no 5.626, de 22 Dez 2005. Regulamenta a Lei no 10.436, de 24 Abr 2002, 
que dispõe sobre a Língua Brasileira de Sinais - Libras e o artigo 18 da Lei no 10.098, de 19 de dezembro de 2000. Brasília, 2005.

. Lei no13. 146, de 6 de julho de 2015. Instituto a Lei Brasileira de Inclusão da Pessoa com Deficiência (Estatuto da Pessoa com Deficiência). Brasília, 2015.

CASTRO, R. G. Libras: uma ponte para comunicação entre pais ouvintes e filhos surdos. Trabalho de Conclusão de Curso (Especialização em Educação Especial Infantil e Fundamental). Maringá: Universidade Estadual de Maringá, 1999.

CASTRO, J. Ir e vir. Acessibilidade: compromisso de cada um. Campo Grande/MS: Gibim, 2013.

CHOI, Daniel et al. PEREIRA, Maria Cristina da Cunha (Org). Libras: conhecimento além dos sinais. SP: Pearson Prentice Hall, 2011.

CHOMSKY, N. Linguagem e pensamento. RJ: Vozes, 1971.

CORDEIRO, Jéssica Lima, SILVA, Maysa Sousa. O ensino de ciências e biologia na educação dos surdos: desafios e perspectivas para uma melhor educação inclusiva. Revista Científica Multidisciplinar Núcleo do Conhecimento. Ano 03, Ed. 08, Vol. 14, pp. 86-100, Ago. de 2018. ISSN:2448-0959

DORZIAT, A. O outro da educação: Pensando a surdez com base nos temas identidade/diferença, currículo e inclusão. Petrópolis, RJ: Vozes, 2009.

FELIPE, T. A.; MONTEIRO, M. S. Libras em contexto: curso básico, livro do professor. 6. ed. Brasília: Ministério da Educação, Secretaria de Educação Especial, 2006.

FERNADES, Sueli. Educação de surdos. Curitiba: InterSaberes, 2012.

GOMES, P. C.; MINGUILI, M. G. Inclusão escolar na percepção de professores do município de Dois Córregos, São Paulo. Camine: Caminhos da Educação, v. 6, p. 1-29, 2014.

GOMES, P. C.; BASSO, S. P. S. O ensino de biologia mediado por LIBRAS: perspectivas de licenciandos em Ciências Biológicas. Trilhas pedagógicas, v.4, n4, P. 40-63, 2014.

LACERDA, C. B. F. de; ALBRES, N. de A.; DRAGO, S.L dos S. Política para uma educação bilíngue e inclusiva a alunos surdos no município de São Paulo. Educ. Pesqui, São Paulo, v. 39, n. 1 p. 65-80, jan./mar. 2013. Disponível em: <http://www.scielo.br/pdf/ep/v39n1/v39n1a05>. Acesso em 30 de Nov. de 2018.

LACERDA, C. B. F. de; SANTOS, L. F. Tenho um aluno surdo, e agora? Introdução à libras e 
educação de surdos. 1. ed. São Carlos: EDUFSCar, 2013. v. 1. 254p.

LOPES, V. G. Linguagem do Corpo e Movimento. Curitiba, PR: FAEL, 2006.

MENDES, E.G. Perspectiva para a construção da escola inclusiva no Brasil. In: PALHARES, M.S.; MARINS, S.C.F. Escola inclusiva. São Carlos: EdUFSCar, 2002: 61-85.

QUADROS, R. M. de. Educação de Surdos: a aquisição da linguagem. Porto Alegre: Artmed, 1997. p. 27.

QUADROS, R. M. de. Aquisição de L2: o contexto da pessoa surda. In: III SEMINÁRIO INTERNACIONAL DE LINGÜÍSTICA, 1996, Porto Alegre. Anais do III Seminário Internacional e Lingüística. Porto Alegre: Gráfica Epecê, 1999. v.1. p.67-74.

QUADROS, R. M. de.; KARNOPP, L.B. Língua de sinais brasileira: estudos linguísticos. Porto Alegre: Artmed, 2004.

SANTANA, A.P. Surdez e linguagem: aspectos e implicações neurolinguísticas. SP: Plexus, 2007.

SANTIAGO, N. C. O ensino e a Aprendizagem das Ciências dos Alunos com Surdez. Monografia de Especialização Universidade Tecnológica Federal do Paraná Diretoria De Pesquisa e PósGraduação Especialização em Ensino De Ciências. Disponível em: <http://repositorio.roca.utfpr.edu.br/jspui/bitstream/1/4383/1/MD_ENSCIE_II_2014_66.pdf>. Acesso em: 06 de Dez. de 2018.

SILVA, C. F. e; GAIA. M. C. de M. Educação inclusiva e o ensino de ciências. Disponível em:< file:///C:/Users/MASTER/Downloads/402-1212-1- PB\%20(3). pdf>. Acesso em 19 de mar. de 2019.

SKILAR, C. B. A surdez: um olhar sobre as diferenças. Porto Alegre: Mediação, 1998. p. 38.

UNESCO. Conferência Mundial de Educação para Todos. Jomtien, 1990.

Data de submissão: 06/04/2019. Data de aprovação: 21/05/2019. 